into their courses, which has increased the "use statistics" in the department exponentially (and has also, the authors warn, impacted the staff workflow dramatically). Of potential use to similar institutions is the chapter by Laura Baudot and Wendy Hyman (Oberlin College) about "Building a Book Studies Program at a Liberal Arts College"; they conducted a Mellon 23 workshop and hope that their study "has illustrated the initial steps that can be taken to set up a book studies program, the various players that need to be involved, the necessity of collaboration between faculty and librarians, and the advantages of following up on meetings and ideas relatively quickly."

In the "Work" section, Marianne Henson (Bryn Mawr College) offers some excellent advice related to having students curate exhibitions in "Real Objects, Real Spaces, Real Expertise: An Undergraduate Seminar Curates an Exhibition on the Medieval Book of Hours." Similarly, Malinda Triller (Dickinson College) presents a useful study for the 21st-century curator in her article on "Social Networking Software in the Archives: Using Blogs to Engage Students with Primary Sources." Finally, I want to notice an inspiring study by Christina Connor and Stephen Rice (Ramapo College of New Jersey) on “The American History Textbook Project: The Making of a Student-Centered Special Collection at a Public Liberal Arts College," which actually created student-driven acquisitions for a research collection, a fabulous way to get students invested in an institution.

There is something in Past or Portal? for anyone working in special collections who wishes to engage students with book and printing history, manuscripts and archives, digital humanities, literature, history, or even the history of science. It is a superb sourcebook, and I would suggest that my colleagues buy two copies - one for their collection, and one as a "working" copy to be kept close at hand and used like a cookbook in a kitchen. -Richard J. Ring, Trinity College.

\section{Library Leadership in the United States} and Europe: A Comparative Study of Academic and Public Libraries. Eds. Peter Hernon and Niels Ole Pors. Santa Barbara, Calif.: Libraries Unlimited, an imprint of ABC-CLIO, LLC, 2013. 231p. paper, $\$ 60.00$ (ISBN 978-1-61069126-0).

Libraries Unlimited, an imprint of ABCCLIO, can always be counted on for excellent publications that support the practice of all areas of librarianship. Although those interested in leadership might find some of the theories covered in this book useful, their application is more scholarly and theoretical than practical. This is logical, since both of the editors are highly respected scholars of library leadership and management, and much of the book looks at the library leadership landscape across two continents. Professor Hernon represents the United States perspective while Professor Pors and the other four contributors represent the European perspective.

The book is divided into four parts: an introduction, an overview of leadership in the United States and Europe, themes, and a conclusion. The overview and the themes include most of the chapters. The introduction and the overview spends a significant amount of time discussing leadership theory and frames many organizational dynamics and management issues within these different theories. Hernon's chapter on library leadership in the United States is comprehensive: he explores how the profession is attempting to address the need for ongoing development of leaders. The remaining overview chapters deal almost entirely with Europe. Again, there is a lot of time spent talking about different leadership and organizational theories, as well as management practices. It is within these chapters that the cultures of the different countries begin to be explored. Culture is an underlying theme throughout the entire book and it is appropriately given ample discussion under the themes section of the book. The work of a select few 
international studies of leadership does dominate this discussion.

It is in the overview section that the reader gets the most library leadership-focused discussion. The general leadership discussion does provide good background information about getting into the library leadership in specific European countries. Two chapters that focus on the Scandinavian countries give the most in-depth research on library leadership. This is where you will find the clearest comparative work as qualitative and quantitative data on Denmark, Norway, and Sweden are presented side by side. A chapter about the United Kingdom is much less about library leadership there and much more about leadership during a period of austerity. Although the challenges of leading during such a period are explored in depth, the fact that the title of the chapter places it in the United Kingdom seems to have no real relevance other than it being a country going through economic challenges, much like the rest of the world at the time. All of the other European countries receive just tertiary discussion with respect to libraries, whereas the general culture discussion is a bit more inclusive.

The themes section of the book covers five major topics: driving forces, culture, personality, followers, and outcomes assessment. These chapters are written by the editors and most are based on and are expanded versions of previous works they have written. Each of these chapters, like much of the book, uses others' research to explore these topics. Leadership and management theories are used to frame the discussions. Although libraries are mentioned in all of the chapters, the chapter on driving forces and the chapter on followers are generalized discussions of leadership. The chapters on culture and personality do include more substantial library leadership discussions. Like previous chapters, most of this discussion focuses on the research done around libraries in Scandinavian countries. The discussion of outcomes assessment is particularly good and looks at many kinds of libraries in more countries than other chapters. This discussion includes information on how and why the different libraries are conducting assessments.

In the final chapters, one thing that the editors make clear is the dearth of leadership research with a library focus and the inadequacy of the research already done to fill that void. For someone interested in doing this kind of research, this problem is framed in such a way that the book outlines many different research ideas. The concluding chapters offer a very rare opportunity to look into the minds of several of the top scholars in this field and discover many viable research ideas yet to be studied. Based on the discussion during most of the book, it is understandable why this was included. At the end of each chapter, there is a list of notes and citations. The book also includes a bibliography at the end of the book and is divided by the format of the resource cited: articles, books, chapters, reports, and so on.

Lastly, the subtitle of the book indicates that it is A Comparative Study of Academic and Public Libraries. Throughout many of the chapters in the book there are comparisons made between leadership in academic and public libraries in specific countries. There are also comparisons between some countries. Yet it is difficult to determine what the primary comparative focus is since the title and subtitle are not clear enough to differentiate and the content of the book, except for a few chapters, does not go into as much depth as the subtitle suggests. Plus the extensive discussion of culture raises the question of whether it is culture or leadership that is being compared. Nonetheless, this is an excellent scholarly work that addresses a topic that is rarely covered in the literature. Leadership and culture are explored in depth, and the theories frame the discussions around libraries. Anyone studying library leadership and management would find this a very useful book. Those who have a solid background in leadership theory may find some chapters redundant. -Mark E. Shelton, Harvard University. 